\title{
Transient Critical Heat Fluxes of Subcooled Water Flow Boiling in a SUS304-CIRCULAR Tube with Twisted-Tape Insert*
}

\author{
Koichi HATA**, Yasuyuki SHIRAI*** and Suguru MASUZAKI**** \\ ** Institute of Advanced Energy, Kyoto Univ., \\ Gokasho, Uji, Kyoto 611-0011, Japan \\ E-mail: hata@iae.kyoto-u.ac.jp \\ *** Dept. of Energy Science and Technology, Kyoto Univ., \\ Sakyo-ku, Kyoto 606-8501, Japan \\ **** National Institute for Fusion Science, \\ 322-6 Oroshi-cho, Toki, Gifu 509-5292, Japan
}

\begin{abstract}
The transient critical heat fluxes (transient CHFs) in a SUS304-circular tube with twisted-tape insert are systematically measured for mass velocities ( $G=3997.79$ to $13419.8 \mathrm{~kg} / \mathrm{m}^{2} \mathrm{~s}$ ), inlet liquid temperatures $\left(T_{i n}=293.55\right.$ to $300.85 \mathrm{~K}$ ), outlet pressures $\left(P_{\text {out }}=825.19\right.$ to $\left.860.95 \mathrm{kPa}\right)$ and exponentially increasing heat inputs $\left(Q=Q_{0} \exp (t / \tau), \tau=26.85 \mathrm{~ms}\right.$ to $\left.8.42 \mathrm{~s}\right)$ by the experimental water loop comprised of a multistage canned-type circulation pump controlled by an inverter. The SUS304 test tube of inner diameter $(d=6 \mathrm{~mm})$, heated length $(L=59.4 \mathrm{~mm})$, effective length $\left(L_{\text {eff }}=49.4 \mathrm{~mm}\right), L / d(=9.9), L_{\text {eff }} / d(=8.23)$ and wall thickness $(\delta=0.5$ $\mathrm{mm})$ with average surface roughness $(R a=3.89 \mu \mathrm{m})$ is used in this work. The SUS304 twisted-tape with width $(w=5.6 \mathrm{~mm})$, thickness $\left(\delta_{T}=0.6 \mathrm{~mm}\right)$, total length $(l=372 \mathrm{~mm})$ and twist ratio, $y\left[=H / d=\left(\right.\right.$ pitch of $180^{\circ}$ rotation $\left.) / d\right]$, of 3.37 is used. The transient CHFs for a SUS304-circular tube with twisted-tape insert are compared with authors' steady-state CHF data for a SUS304-circular tube with various twisted-tape inserts, their transient CHF data for the empty SUS304-tube and the values calculated by authors' steady-state CHF correlations for the test tubes with various twisted-tape inserts and their transient CHF correlations for the empty test tubes. The influences of twisted-tape insert, heating rate and swirl velocity on the transient CHF are investigated into details and the widely and precisely predictable correlations of the transient CHF for the test tube with twisted-tape insert are given based on the experimental data. The correlations can describe the transient CHFs for a SUS304-circular tube with twisted-tape of $y=3.37$ obtained in this work within -27 to $7.9 \%$ difference.
\end{abstract}

Key words: Transient Critical Heat Flux, Subcooled Flow Boiling, Heating Rate, SUS304-Circular Tube, Twisted-Tape Insert

\section{Introduction}

The influence of heating rate on subcooled flow boiling critical heat fluxes (CHFs) in a test tube with twisted-tape insert is necessary to investigate the reliability of a divertor in a nuclear fusion facility for short pulse high heat flux test mode. The nuclear fusion facility has two operation modes. One is the steady-state operation mode, and the other is the transient one. The plasma facing material in transient operation mode is exposed to a heat load three times larger or more than during steady-state operation for several seconds. The knowledge of transient high heat flux heat removal with various plasma heating rate becomes very important to take the heat out of the plasma facing material.

Many researchers have experimentally studied the steady-state CHFs uniformly heated

${ }^{*}$ Received 23 Jan., 2013 (№. 13-0021) [DOI: 10.1299/jpes.7.122]

Copyright $@ 2013$ by JSME 
on the test tube with twisted-tape insert by a steadily increasing current, shown that the test tube with twisted-tape insert provide considerable enhancement of CHFs in subcooled flow boiling and given the correlations for calculating CHFs on the test tube with twisted-tape insert ${ }^{(1-9)}$. We have supposed that the enhancement of CHFs for the test tube with twisted-tape insert at a fixed mass velocity will be due to reduction of conductive sub-layer thickness on heated surface of test tube and due to an increase in liquid flow velocity from straight flow to swirl one, not new mechanism of heat transfer crisis. And furthermore, we have also supposed that flow velocity will affect the incipient boiling superheat and the nucleate boiling heat transfer up to the CHF. Incipient boiling superheat may shift to a very high value at higher flow velocity and a direct transition to film boiling or a trend of a decrease in CHF with a delay of boiling initiation may occur due to the heterogeneous spontaneous nucleation but not due to the hydro-dynamic instability. The accurate measurement for the subcooled boiling heat transfer up to the CHF is necessary to clarify a change in the mechanism of CHF.

Recently, we have systematically measured the turbulent heat transfer (THT), the subcooled boiling heat transfer (SBHT) and the steady-state critical heat fluxes (steady-state CHFs) in the SUS304-circular tubes with various twisted-tape inserts for mass velocities $\left(G=4016\right.$ to $13950 \mathrm{~kg} / \mathrm{m}^{2} \mathrm{~s}$ ), inlet liquid temperatures ( $T_{i n}=285.8$ to $364.0 \mathrm{~K}$ ), outlet pressures $\left(P_{\text {out }}=764.8\right.$ to $\left.889.0 \mathrm{kPa}\right)$ and exponentially increasing heat input $\left(Q=Q_{0}\right.$ $\exp (t / \tau), \tau=8.5 \mathrm{~s})$ by the experimental water loop comprised of a multistage canned-type circulation pump controlled by an inverter ${ }^{(10-12)}$. The SUS304 test tube of inner diameter $(d=6 \mathrm{~mm})$, heated length $(L=59.5 \mathrm{~mm})$, effective length $\left(L_{\text {eff }}=49.1 \mathrm{~mm}\right), L / d(=9.92), L_{\text {eff }} / d$ $(=8.18)$ and wall thickness $(\delta=0.5 \mathrm{~mm})$ with average surface roughness $(R a=3.89 \mu \mathrm{m})$ is used in this work. The SUS304 twisted-tapes with widths ( $w=5.3$ to $5.6 \mathrm{~mm}$ ), thickness $\left(\delta_{T}=0.6 \mathrm{~mm}\right)$, total length $(l=372 \mathrm{~mm})$ and twist ratios, $y\left[=H / d=\left(\right.\right.$ pitch of $180^{\circ}$ rotation $\left.) / d\right]$, of $2.39,3.39$ and 4.45 are used. The influences of the twisted-tape insert, the twist ratio and the swirl velocity on the THT, the SBHT and the CHFs are investigated into details. And the steady-state CHF correlations against inlet and outlet subcoolings for the test tubes with various twisted-tape inserts are derived as follows due to the effect of boiling number based on swirl velocity, $B o_{c r, s w}$, and Weber number based on swirl velocity, $W e_{s w}$.

$$
\begin{aligned}
& B o_{c r, s w}=C_{1} D^{*-0.1} W e_{s w}^{-0.3}\left(\frac{L}{d}\right)^{-0.1} e^{-\frac{(L / d)}{C_{2} R e_{d}^{0.4}}} S c^{* C_{3}} \\
& \text { if inlet subcooling is known }\left(\Delta T_{s u b, i n} \geq 40 \mathrm{~K}\right) \\
& B o_{c r, s w}=0.082 D^{*-0.1} W_{s w}^{-0.3}\left(\frac{L}{d}\right)^{-0.1} S c^{0.7}
\end{aligned}
$$

if outlet subcooling is known $\left(\Delta T_{\text {sub,out }} \geq 30 \mathrm{~K}\right)$

where $B o_{c r, s w}=\frac{q_{c r, s u b, s t}}{G h_{f g}} \times \frac{\left(\pi d^{2}-4 w \delta_{T}\right)}{\pi d^{2}} \times \frac{2 y}{\left(4 y^{2}+2 \pi^{2}\right)^{0.5}}$

$$
W e_{s w}=\frac{G^{2} d}{\rho_{l} \sigma} \times\left(\frac{\pi d^{2}}{\pi d^{2}-4 w \delta_{T}}\right)^{2} \times\left[\frac{\left(4 y^{2}+2 \pi^{2}\right)^{0.5}}{2 y}\right]^{2}
$$

$C_{l}=0.082, C_{2}=0.53$ and $C_{3}=0.7$ for $L / d \leq$ around 40 and $C_{I}=0.092, C_{2}=0.85$ and $C_{3}=0.9$ for $L / d>$ around $40 . w, \delta_{T}$ and $y$ are the width of the twisted-tape, the thickness of the twisted-tape and the twist ratio of the twisted-tape $\left[H / d=\left(\right.\right.$ pitch of $180^{\circ}$ rotation $\left.) / d\right]$, respectively. The correlations can describe the CHFs in the SUS304-circular tubes with various twisted-tape inserts within -25 to $+10 \%$ difference. These equations are composed of the same terms, exponents and constants except for a transient term as shown in the transient CHF correlations against inlet and outlet subcoolings for the empty test tubes, Eqs. (5) and (6) ${ }^{(13-15)}$

$$
\begin{array}{r}
B o_{c r}=C_{1} D^{*-0.1} W e^{-0.3}\left(\frac{L}{d}\right)^{-0.1} e^{-\frac{(L / d)}{C_{2} R e_{d}^{0.4}}} S c^{*} C_{3} \times\left(1+11.4 p^{*-0.6}\right) \\
\text { if inlet subcooling is known }\left(\Delta T_{\text {sub,in }} \geq 40 \mathrm{~K}\right) \\
\boldsymbol{B o}_{c r}=0.082 \mathrm{D}^{*-0.1} \mathrm{We}^{-0.3}\left(\frac{L}{d}\right)^{-0.1} S c^{0.7} \times\left(1+6.34 \mathrm{p}^{*-0.6}\right)
\end{array}
$$

if outlet subcooling is known $\left(\Delta T_{\text {sub,out }} \geq 30 \mathrm{~K}\right)$

where $p^{*}$ is the non-dimensional exponential period, $p^{*=}=\tau u /\left\{\sigma / g /\left(\rho_{l}-\rho_{g}\right)\right\}^{0.5}$

The objectives of present study are fivefold. First is to measure the transient CHFs for SUS304-tube with a twisted-tape of twist ratio $(y)$ of 3.37 for the wide ranges of heating rates $(\tau)$, swirl velocities $\left(u_{s w}\right)$ and inlet subcoolings $\left(\Delta T_{s u b, i n}\right)$. Second is to compare the 
above results with the steady-state CHF data for the SUS304-circular tubes with various twisted-tape inserts ${ }^{(10-12)}$ and the transient CHF data for the empty SUS304-tubes previously obtained ${ }^{(13-15)}$. Third is to clarify the influence of twisted-tape insert, heating rate and swirl velocity on the transient CHF. Fourth is to derive the transient CHF correlations against inlet and outlet subcoolings in a SUS304-circular tube with the twisted-tape insert based on the experimental data. Fifth is to discuss the mechanism of the subcooled flow boiling critical heat flux in a circular vertical tube.

\section{Nomenclature}

$a, b, c \quad$ fitted constant

$B o_{c r} \quad=q_{c r, s u b} / G h_{f g}$, boiling number

$B o_{c r, s w}=\frac{\boldsymbol{q}_{c r, s u b, s t}}{\boldsymbol{G} \boldsymbol{h}_{f g}} \times \frac{\left(\pi \boldsymbol{d}^{2}-4 \boldsymbol{w} \delta_{T}\right)}{\pi \boldsymbol{d}^{2}} \times \frac{2 \boldsymbol{y}}{\left(4 \boldsymbol{y}^{2}+2 \pi^{2}\right)^{0.5}}$, boiling number based on swirl velocity

C coefficient in Eq. (20)

$C_{1}, C_{2}, C_{3}$ constant in Eqs. (1), (5) and (24)

$C_{s f} \quad$ coefficient in Eq. (22)

$c \quad$ specific heat, $\mathrm{J} / \mathrm{kg} \mathrm{K}$

$c_{p} \quad$ specific heat at constant pressure, $\mathrm{J} / \mathrm{kg} \mathrm{K}$

$D^{*} \quad=d /\left\{\sigma / g /\left(\rho_{l}-\rho_{g}\right)\right\}^{0.5}$, non-dimensional diameter

$d \quad$ test tube inner diameter, $\mathrm{m}$

$G \quad=\rho_{l} u$, mass velocity, $\mathrm{kg} / \mathrm{m}^{2} \mathrm{~s}$

$g \quad$ acceleration of gravity, $\mathrm{m} / \mathrm{s}^{2}$

$h_{f g} \quad$ latent heat of vaporization, $\mathrm{J} / \mathrm{kg}$

I current flowing through standard resistance, A

$L \quad$ heated length, $\mathrm{m}$

$L_{e} \quad$ entrance length, $\mathrm{m}$

$L_{\text {eff }} \quad$ effective length, $\mathrm{m}$

$L_{i p t} \quad$ distance between inlet pressure transducer and inlet of the heated section, $\mathrm{m}$

$L_{\text {opt }}$

$N u_{d}$

$n$

$P$

$P_{\text {in }}$

$P_{\text {ipt }}$

$P_{\text {out }}$

$P_{\text {opt }}$

$P_{r}$ distance between outlet pressure transducer and outlet of the heated section, $m$ $=h d / \lambda$, Nusselt number

exponent in Eq. (20) pressure, $\mathrm{kPa}$

\section{pressure at inlet of heated section, $\mathrm{kPa}$}

pressure measured by inlet pressure transducer, $\mathrm{kPa}$

pressure at outlet of heated section, $\mathrm{kPa}$

pressure measured by outlet pressure transducer, $\mathrm{kPa}$

$=c_{p} \mu_{l} / \lambda_{l}$, Prandtl number

$p^{*} \quad=\tau u /\left\{\sigma / g /\left(\rho_{l}-\rho_{g}\right)\right\}^{0.5}$, non-dimensional exponential period

$Q \quad$ heat input per unit volume, $\mathrm{W} / \mathrm{m}^{3}$

$Q_{0} \quad$ initial exponential heat input, $\mathrm{W} / \mathrm{m}^{3}$

$q \quad$ heat flux, $\mathrm{W} / \mathrm{m}^{2}$

$q_{c r, s u b, s t} \quad$ steady-state CHF for subcooled condition, $\mathrm{W} / \mathrm{m}^{2}$

$R_{l}$ to $R_{3}$ resistance in a double bridge circuit, $\Omega$

$R a \quad$ average roughness, $\mu \mathrm{m}$

$R e_{d} \quad=G d / \mu_{l}$, Reynolds number

$R e_{s w}=\frac{G d}{\mu_{l}} \times \frac{\pi d^{2}}{\left(\pi d^{2}-4 w \delta_{T}\right)} \times \frac{\left(4 y^{2}+2 \pi^{2}\right)^{0.5}}{2 y}$, Reynolds number based on swirl velocity

$R \max \quad$ maximum roughness depth, $\mu \mathrm{m}$

$R z \quad$ mean roughness depth, $\mu \mathrm{m}$

$r$ radius, $\mathrm{m}$

$r_{i} \quad$ test tube inner radius, $\mathrm{m}$

$r_{o} \quad$ test tube outer radius, $\mathrm{m}$

$S \quad$ surface area, $\mathrm{m}^{2}$

Sc $\quad=c_{p l}\left(\Delta T_{\text {sub,out }}\right)_{c a l} / h_{f g},=c_{p l} \Delta T_{\text {sub,out }} / h_{f g}$, non-dimensional outlet subcooling

$S c^{*} \quad=c_{p l} \Delta T_{\text {sub,in }} / h_{f g}$, non-dimensional inlet subcooling

$T \quad$ temperature of the test tube, $\mathrm{K}$

$\overline{\boldsymbol{T}} \quad$ average temperature of the test tube, $\mathrm{K}$

$T_{H} \quad$ homogeneous spontaneous nucleation temperature, $\mathrm{K}$

$T_{H E T} \quad$ lower limit of heterogeneous spontaneous nucleation temperature, $\mathrm{K}$

$T_{\text {in }} \quad$ inlet liquid temperature, $\mathrm{K}$

$T_{\text {out }} \quad$ outlet liquid temperature, $\mathrm{K}$

$t$ time, $\mathrm{s}$

$\Delta T_{\text {sat }} \quad=T_{s}-T_{\text {sat }}$, surface superheat, $\mathrm{K}$ 


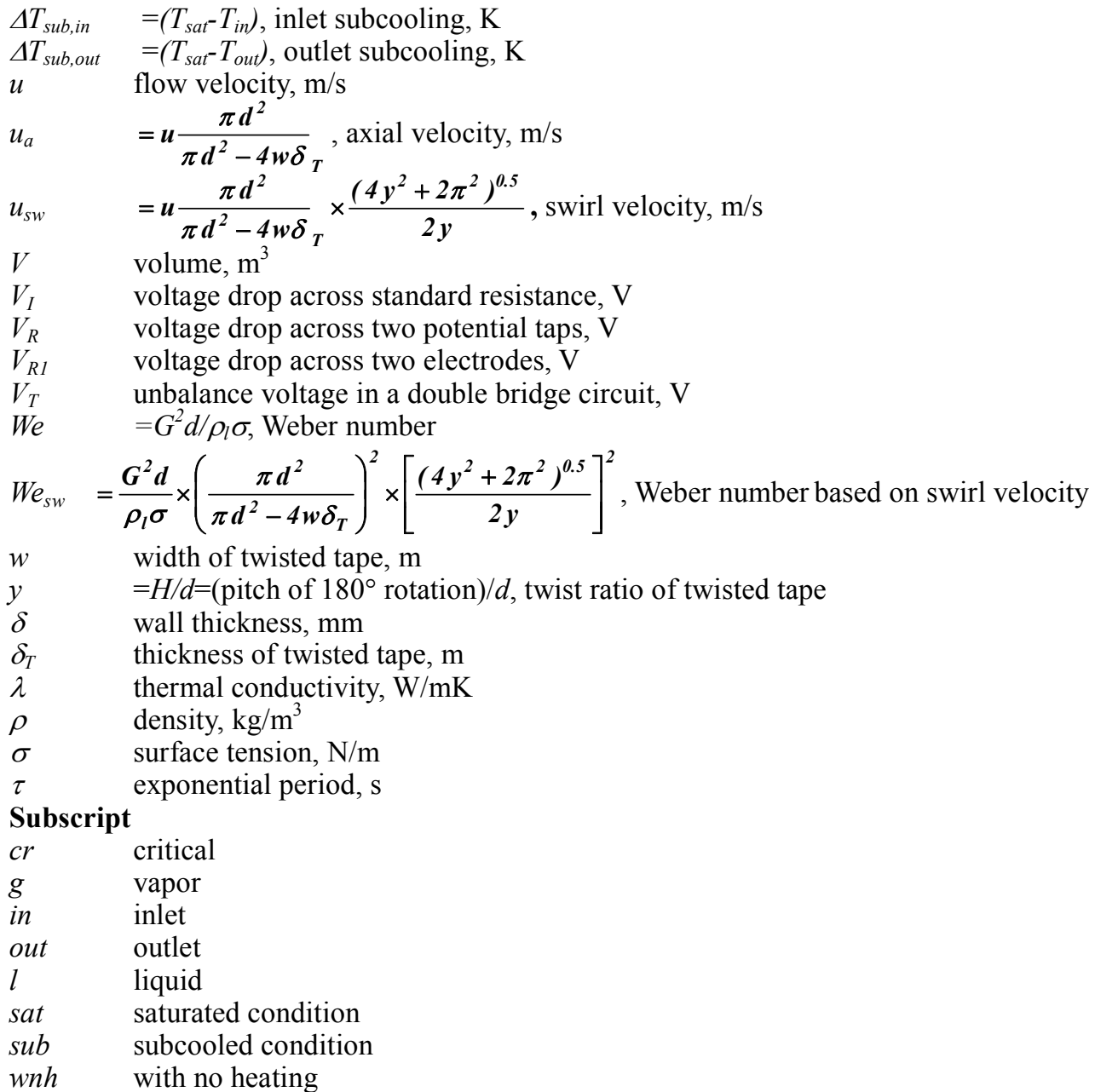

\section{Experimental apparatus and method}

\subsection{Experimental water loop}

The schematic diagram of experimental water loop comprised of the pressurizer is shown in Fig. 1. The loop is made of SUS304 stainless steel and is capable of working up to $2 \mathrm{MPa}$. The loop has five test sections whose inner diameters are 2, 3, 6, 9 and $12 \mathrm{~mm}$. Test sections were vertically oriented with water flowing upward. The test section of the inner diameter of $6 \mathrm{~mm}$ was used in this work. The circulating water was distilled and deionized

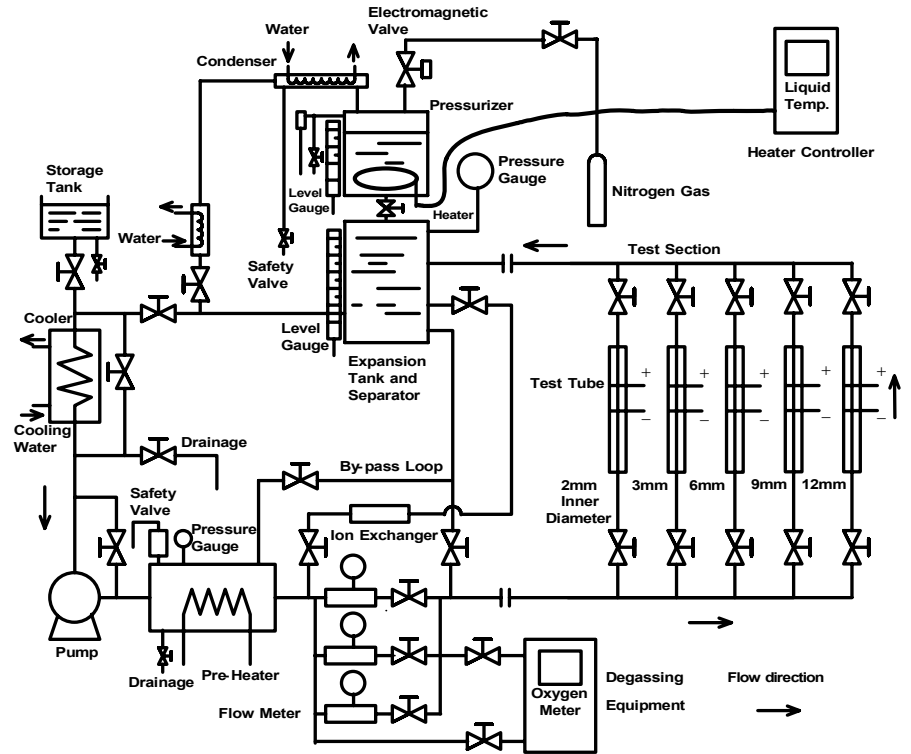

Fig. 1 Schematic diagram of experimental water loop 


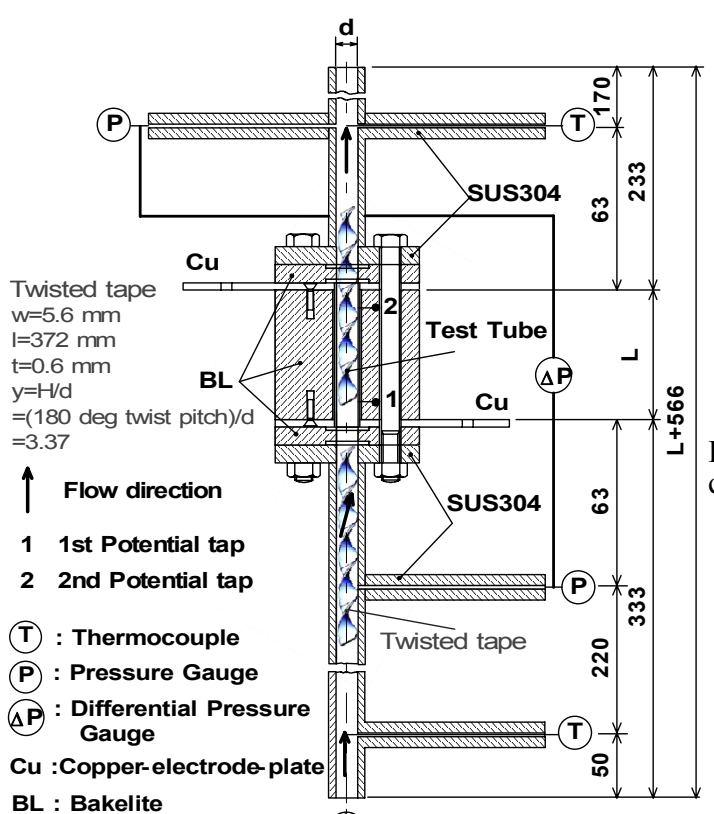

(1)

Fig. 2 Vertical cross-sectional view of $6 \mathrm{~mm}$ inner diameter test section with the twisted-tape insert

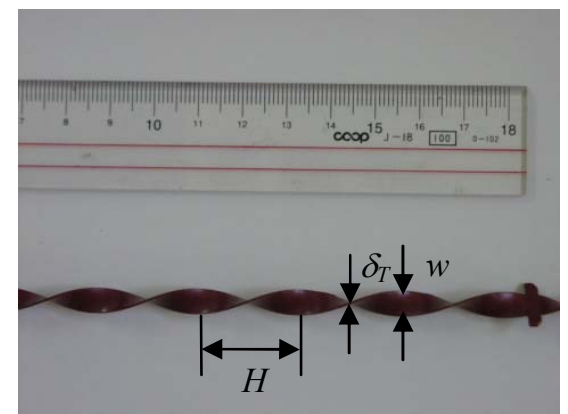

Fig. 3 Photograph of the SUS304 twisted-tape coated with alumina thermal spraying

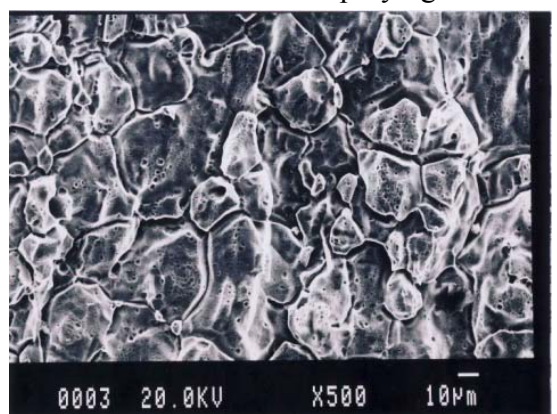

Fig. 4 SEM photograph for the SUS304 test tube of $d=6 \mathrm{~mm}$ with the rough finished inner surface

with about $0.2-\mu \mathrm{S} / \mathrm{cm}$ specific resistivity. The circulating water through the loop was heated or cooled to keep a desired inlet temperature by pre-heater or cooler. The mass velocity was measured by a mass flow meter using a vibration tube (Nitto Seiko, CLEANFLOW 63FS25, Flow range $=100$ and $750 \mathrm{Kg} / \mathrm{min})$. The mass velocity was controlled by regulating the frequency of the three-phase alternating power source to the multistage canned-type circulation pump with high pump head (Nikkiso Co., Ltd., Non-Seal Pump Multi-stage Type VNH12-C4 C-3S7SP, pump flow rate $=12 \mathrm{~m}^{3} / \mathrm{h}$, pump head=250 $\mathrm{m}$ ) with an inverter installed a 4-digit LED monitor (Mitsubishi Electric Corp., Inverter, Model-F720-30K). The pump input frequency shows the net pump input power and pump discharge pressure free of slip loss. The circulating water was pressurized by saturated vapor in the pressurizer in this work. The pressure at the outlet of the test tube was controlled within $\pm 1 \mathrm{kPa}$ of a desired value by using a heater controller of the pressurizer.

\subsection{Test section}

The cross-sectional view of $6 \mathrm{~mm}$ inner diameter test section used in this work is shown in Fig. 2. The SUS304 test tubes with 3 different surface roughnesses have been generally used. The test tubes with rough and smooth finished inner surfaces (RF and SF) are commercially available. The rough finished inner surface was fabricated by annealing the test tube first in the atmosphere of air and was then acidized, while the smooth finished inner surface was fabricated by annealing the test tube in the atmosphere of hydrogen gas. The smooth finished inner surface test tube was polished up to around $25 \mu \mathrm{m}$ deep by the electrolytic abrasive treatment to realize the mirror finished one (MF). The rough finished inner surface test tube (RF) was used in this work. The SUS304 test tube for the test tube inner diameter of $6 \mathrm{~mm}$ and the heated length, $L$, of $59.4 \mathrm{~mm}$ with a SUS304 twisted-tape of twist ratio, $y$, of 3.37 was mainly used. Wall thickness of the test tube, $\delta$, was $0.5 \mathrm{~mm}$. Two fine $0.07-\mathrm{mm}$ diameter platinum wires were spot-welded on the outer surface of the test tube as potential taps. The effective length, $L_{\text {eff }}$, of the test tube between the potential taps on which heat transfer was measured was $49.4 \mathrm{~mm}$. The SUS304 twisted-tape of width $(w=5.6$ $\mathrm{mm})$, thickness $\left(\delta_{T}=0.6 \mathrm{~mm}\right)$, total length $(l=372 \mathrm{~mm})$ and twist ratio $\left[y=H / d=\left(\right.\right.$ pitch of $180^{\circ}$ rotation $) / d=3.37$ ] as shown in Fig. 3 was mainly employed. Various twisted-tape widths $(w=5.3,5.4,5.5$ and $5.6 \mathrm{~mm}$ ) have been used to determine the optimum conditions for test tube heating. The surface of the SUS304 twisted-tape was uniformly coated with alumina thermal spraying for electric insulation in this work. The silver-coated 5-mm thickness copper-electrode-plates to supply heating current were soldered to the surfaces of the both ends of the test tube. The both ends of test tube were electrically isolated from the loop by Bakelite plates of 14-mm thickness. The inner surface condition of the test tube was 
observed by the scanning electron microscope (SEM) photograph (JEOL JXA8600) and inner surface roughness was measured by Tokyo Seimitsu Co., Ltd.'s surface texture measuring instrument (SURFCOM 120A). Figure 4 shows the SEM photograph for the SUS304 test tube of $d=6 \mathrm{~mm}$ with the rough finished inner surface (RF). The inner surface roughness is measured $3.89 \mu \mathrm{m}$ for $R a, 21.42 \mu \mathrm{m}$ for $R \max$ and $15.03 \mu \mathrm{m}$ for $R z$.

\subsection{Method of heating test tube with twisted-tape insert}

The test tube with twisted-tape insert has been heated with an exponentially increasing heat input supplied from a direct current source (Takasago Ltd., NL035-500R, DC 35 V3000 A) through the two copper electrodes shown in Fig. 5. The common specifications of the direct current source are as follows. Constant-voltage $(\mathrm{CV})$ mode regulation is $0.005 \%+3 \mathrm{mV}$ of full scale, $\mathrm{CV}$ mode ripple is $500 \mu \mathrm{V}$ r.m.s. or better and $\mathrm{CV}$ mode transient response time is less than $200 \mu \mathrm{sec}$ (Typical) against $5 \%$ to full range change of load. The transient CHFs, $q_{c r, s u b}$, were realized by the exponentially increasing heat input to the test tube with twisted-tape insert. At the transient CHF, the test tube average temperature rapidly increases. The current for the heat input to the test tube with twisted-tape insert was automatically cut off when the measured average temperature increased up to the preset temperature, which was several tens of Kelvin higher than corresponding transient CHF surface temperature. This procedure avoided actual burnout of the test tube.

\subsection{Measurement of transient CHF, temperature and pressure for test tube with twisted-tape insert}

The transient average temperature of the test tube with twisted-tape insert, $\overline{\boldsymbol{T}}(\boldsymbol{t})$, was measured with resistance thermometry participating as a branch of a double bridge circuit for the temperature measurement. The output voltages from the bridge circuit, $V_{T}(t)$, together with the voltage drop across the potential taps of the test tube with twisted-tape insert, $V_{R}(t)=I(t) R_{T}(t)$, and across a standard resistance, $V_{I}(t)=I(t) R_{s}$, were amplified and then were sent via a $\mathrm{D} / \mathrm{A}$ converter to a digital computer. The unbalance voltage, $V_{T}(t)$, is expressed by means of Ohm's low as the following form.

$$
V_{T}(t)=\frac{I(t)\left\{R_{T}(t) \times R_{2}-R_{1} \times R_{3}\right\}}{R_{2}+R_{3}}
$$

These voltages were simultaneously sampled at a constant interval ranging from $120 \mu$ s to $200 \mathrm{~ms}$. The average temperature of the test tube with twisted-tape insert between the potential taps was calculated with the aid of previously calibrated resistance-temperature relation, $R_{T}(t)=a\left(1+b \overline{\boldsymbol{T}}(t)+c \overline{\boldsymbol{T}}(t)^{2}\right)$. The average temperatures of the test tube between the two electrodes, $V_{R I}(t)$, were compared with those between potential taps, $V_{R}(t)$, and much difference for a heat loss could not be clearly observed in high subcooling range. The heat generation rate, $Q(t)=I^{2}(t) R_{T}(t)$, in the test tube with twisted-tape insert between the

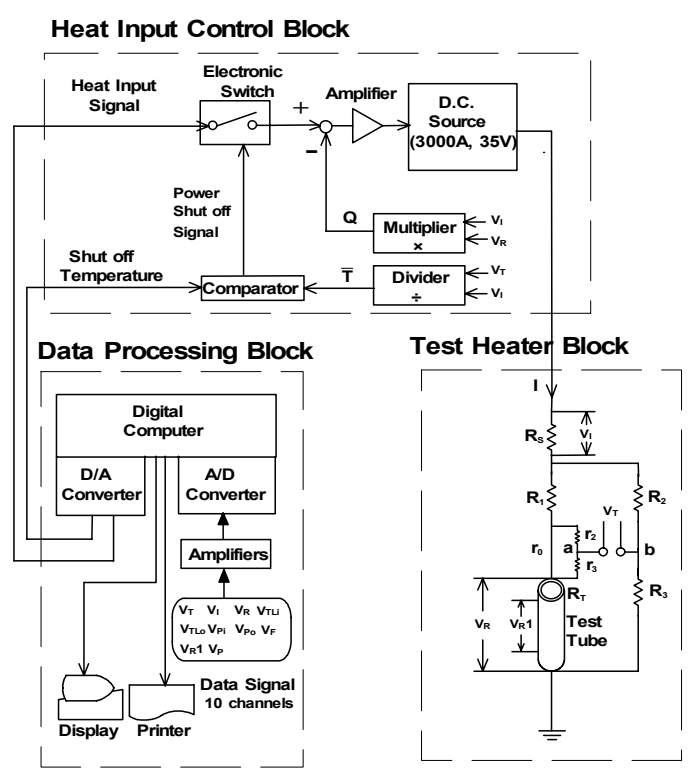

Fig. 5 Measurement and data processing system 
potential taps was calculated from the measured voltage difference between the potential taps of the test tube and the standard resistance, $V_{R}(t)$ and $V_{I}(t)$. The surface heat flux, $q(t)$, is the difference between the heat generation rate per unit surface area, $Q(t)$, and the rate of change of energy storage in the test tube obtained from the faired average temperature versus time curve as follows:

$$
q(t)=\frac{V}{S}\left(Q(t)-\rho c \frac{d \bar{T}}{d t}\right)
$$

where $\rho, c, V$ and $S$ are the density, the specific heat, the volume and the inner surface area of the test tube, respectively.

The heater inner surface temperatures between the two potential taps, $T_{s}(t)$, were also obtained by solving the unsteady heat conduction equation in the test tube under the conditions of measured average temperature, $\bar{T}(t)$, and heat generation rate per unit surface area, $Q(t)$, of the test tube with twisted-tape insert. All the calculations of the inner surface temperature were made by using the PHOENICS code ${ }^{(16)}$. Basic unsteady two-dimensional heat conduction equation for the test tube with twisted-tape insert is as follows:

$$
\rho c \frac{\partial T}{\partial t}=\frac{1}{r} \frac{\partial}{\partial r}\left(\lambda r \frac{\partial T}{\partial r}\right)+\frac{1}{r} \frac{\partial}{\partial \theta}\left(\frac{\lambda}{r} \frac{\partial T}{\partial \theta}\right)+Q(t)
$$

The calculation domain from test tube inner radius, $r_{i}$, to test tube outer radius, $r_{o}$, is radially divided into 500 grid points $(\Delta r=1 \mu \mathrm{m})$ and the time step, $\Delta t$, is given much smaller than $0.45 \mathrm{~ms}$. The unsteady equation is numerically analyzed together with the following boundary conditions.

$$
\begin{aligned}
& q(t)=-\left.\lambda \frac{\partial T}{\partial r}\right|_{r=r_{i}} \\
& \left.\frac{\partial T}{\partial r}\right|_{r=r_{o}}=0
\end{aligned}
$$

Furthermore, the steady-state inner surface temperature, $T_{s}$, was also obtained by solving the heat conduction equation in the test tube under the conditions of measured average temperature, $\overline{\boldsymbol{T}}$, and surface heat flux, $q$, of the test tube with twisted-tape insert. The temperatures of the heater inner surface, $T_{s}$, can be described by the steady one-dimensional heat conduction equation as follows:

$$
\begin{aligned}
T_{s}= & T\left(r_{i}\right)=\bar{T}-\frac{q r_{i}}{4\left(r_{o}^{2}-r_{i}^{2}\right)^{2} \lambda} \times\left[4 r_{o}^{2}\left\{r_{o}^{2}\left(\ln r_{o}-\frac{1}{2}\right)-r_{i}^{2}\left(\ln r_{i}-\frac{1}{2}\right)\right\}-\left(r_{o}^{4}-r_{i}^{4}\right)\right] \\
& -\frac{q r_{i}}{2\left(r_{o}^{2}-r_{i}^{2}\right) \lambda}\left(r_{i}^{2}-2 r_{o}^{2} \ln r_{i}\right)
\end{aligned}
$$

where $\overline{\boldsymbol{T}}, q, \lambda, r_{i}$ and $r_{o}$ are average temperature of the test tube, heat flux, thermal conductivity, test tube inner radius and test tube outer radius, respectively.

In case of the $6 \mathrm{~mm}$ inner diameter test section, before entering the test tube with twisted-tape insert, the test water flows through the tube with the same inner diameter of the test tube to form the fully developed velocity profile. The entrance tube length, $l_{e}$, with the twisted-tape insert is given $248 \mathrm{~mm}\left(l_{e} / d=41.3\right)$. The values of $l_{e} / d$ for $d=6 \mathrm{~mm}$ in which the center line velocity reaches $99 \%$ of the maximum value for turbulence flow were obtained ranging from 9.8 to 21.9 by the correlation of Brodkey and Hershey ${ }^{(17)}$ as follows:

$$
\frac{l_{e}}{d}=0.693 \operatorname{Re}_{d}^{1 / 4}
$$

The swirl velocity, $u_{s w}$, was defined by the inlet flow velocity, $u$, in consideration of the decrement of flow cross section and the increment of flow length by the twisted-tape as follows ${ }^{(1)}$ :

$$
u_{s w}=u \frac{\pi d^{2}}{\pi d^{2}-4 w \delta_{T}} \times \frac{\left(4 y^{2}+\pi^{2}\right)^{0.5}}{2 y}
$$

where $w, \delta_{T}$ and $y$ are the width of the twisted-tape, the thickness of the twisted-tape and the twist ratio of the twisted-tape $\left[H / d=\left(\right.\right.$ pitch of $180^{\circ}$ rotation $\left.) / d\right]$, respectively. And furthermore, Kabata et al. considered the effect of the circumferential velocity due to the twisted-tape. The swirl velocity, $u_{s w}$, was corrected as follows ${ }^{(6)}$ :

$$
u_{s w}=u \frac{\pi d^{2}}{\pi d^{2}-4 w \delta_{T}} \times \frac{\left(4 y^{2}+2 \pi^{2}\right)^{0.5}}{2 y}
$$

The inlet and outlet liquid temperatures were measured by 1-mm o.d., sheathed, K-type thermocouples (Nimblox, sheath material: SUS316, hot junction: ground, response time 
(63.2\%): $46.5 \mathrm{~ms}$ ) which are located at the centerline of the tube at the upper and lower stream points of 283 and $63 \mathrm{~mm}$ from the test tube inlet and outlet points. The inlet and outlet pressures were measured by the strain gauge transducers (Kyowa Electronic Instruments Co., Ltd., PHS-20A, Natural frequency: approximately $30 \mathrm{kHz}$ ), which were located near the entrance of conduit at upper and lower stream points of $63 \mathrm{~mm}$ from the test tube inlet and outlet points. The thermocouples and the transducers were installed in the conduits as shown in Fig. 2. The inlet and outlet pressures were calculated from the pressures measured by inlet and outlet pressure transducers as follows:

$$
\begin{aligned}
& \boldsymbol{P}_{\text {in }}=\boldsymbol{P}_{\text {ipt }}-\left\{\left(\boldsymbol{P}_{i p t}\right)_{\text {wh }}-\left(\boldsymbol{P}_{\text {opt }}\right)_{\text {whh }}\right\} \times \frac{\boldsymbol{L}_{\text {ipt }}}{\boldsymbol{L}_{\text {ipt }}+\boldsymbol{L}+\boldsymbol{L}_{\text {opt }}} \\
& \boldsymbol{P}_{\text {out }}=\boldsymbol{P}_{\text {in }}-\left(\boldsymbol{P}_{\text {in }}-\boldsymbol{P}_{\text {opt }}\right) \times \frac{\boldsymbol{L}}{\boldsymbol{L}+\boldsymbol{L}_{\text {opt }}}
\end{aligned}
$$

where $L_{i p t}=0.063 \mathrm{~m}$ and $L_{o p t}=0.063 \mathrm{~m}$. The differential pressure between the conduits at upper and lower stream points of $63 \mathrm{~mm}$ from the test tube inlet and outlet points were measured by the differential pressure transducer (Kyowa Electronic Instruments Co., Ltd., PD-500GA, Natural frequency: approximately $230 \mathrm{kHz}$ ).

Experimental errors are estimated to be $\pm 1 \mathrm{~K}$ in inner tube surface temperature and $\pm 2 \%$ in heat flux. Mass velocity, inlet and outlet subcoolings, inlet and outlet pressures, differential pressure and exponential period were measured within the accuracy $\pm 2 \%, \pm 1 \mathrm{~K}$, $\pm 4 \mathrm{kPa}, \pm 0.15 \mathrm{kPa}$ and $\pm 2 \%$, respectively.

\section{Experimental results and discussion}

\subsection{Experimental conditions}

Transient heat transfer processes and CHFs that caused by exponentially increasing heat input, $Q_{0} \exp (t / \tau)$, were measured for the SUS304-circular tube with a SUS304 twisted-tape insert. The exponential periods, $\tau$, of the heat input ranged from $26.85 \mathrm{~ms}$ to $8.42 \mathrm{~s}$. The decrease of the exponential period means an increase in the rate of increasing heat input. The initial experimental conditions such as mass velocity, inlet subcooling, outlet pressure and exponential period in the flow boiling heat transfer and transient $\mathrm{CHF}$ experiments were determined independently each other before each experimental run.

The experimental conditions were as follows:

Test Tube Number

Test Tube Material

THD-F190

Inner Diameter $(d)$

SUS304

Heated Length $(L)$

$6 \mathrm{~mm}$

Effective Length $\left(L_{e f f}\right)$

$59.4 \mathrm{~mm}$

$L / d$

$49.4 \mathrm{~mm}$

$L_{\text {eff }} / d$

9.9

8.23

Wall Thickness $(\delta)$

Surface Condition

Surface Roughness

Twisted-Tape Number

Twisted-Tape Material

Width $(w)$

Thickness $\left(\delta_{T}\right)$

Total Length $(l)$

Pitch of $180^{\circ}$ rotation $(H)$

$0.5 \mathrm{~mm}$

Rough finished inner surface (commercial finish)

$3.89 \mu \mathrm{m}$ for $R a, 21.42 \mu \mathrm{m}$ for $R \max$ and $15.03 \mu \mathrm{m}$ for $R z$ TT4

SUS304

$5.6 \mathrm{~mm}$

$0.6 \mathrm{~mm}$

$372 \mathrm{~mm}$

Electric Insulation

Pump Input Frequency $\left(f_{p i}\right)$

Mass Velocity $(G)$

Flow Velocity $(u)$

Axial Velocity $\left(u_{a}\right)$

Swirl Velocity $\left(u_{s w}\right)$

Reynolds Number $\left(R e_{d}\right)$

otation) $/ d$ ]

3.37

8.35 to $33.5 \mathrm{~Hz}$

Alumina thermal spraying

3997.79 to $13419.8 \mathrm{~kg} / \mathrm{m}^{2} \mathrm{~s}$

$4.0,6.9,9.9$ and $13.3 \mathrm{~m} / \mathrm{s}$

4.51 to $15.15 \mathrm{~m} / \mathrm{s}$

5.37 to $18.11 \mathrm{~m} / \mathrm{s}$

$1.55 \times 10^{5}$ to $5.22 \times 10^{5}$

Reynolds Number based on Swirl Velocity $\left(R e_{s w}\right) \quad 1.86 \times 10^{5}$ to $6.24 \times 10^{5}$

Inlet Pressure $\left(P_{\text {in }}\right)$

Outlet Pressure $\left(P_{\text {out }}\right)$

852.02 to $989.96 \mathrm{kPa}$

Inlet Subcooling $\left(\Delta T_{\text {sub,in }}\right)$

825.19 to $860.95 \mathrm{kPa}$

149.02 to $161.54 \mathrm{~K}$ 


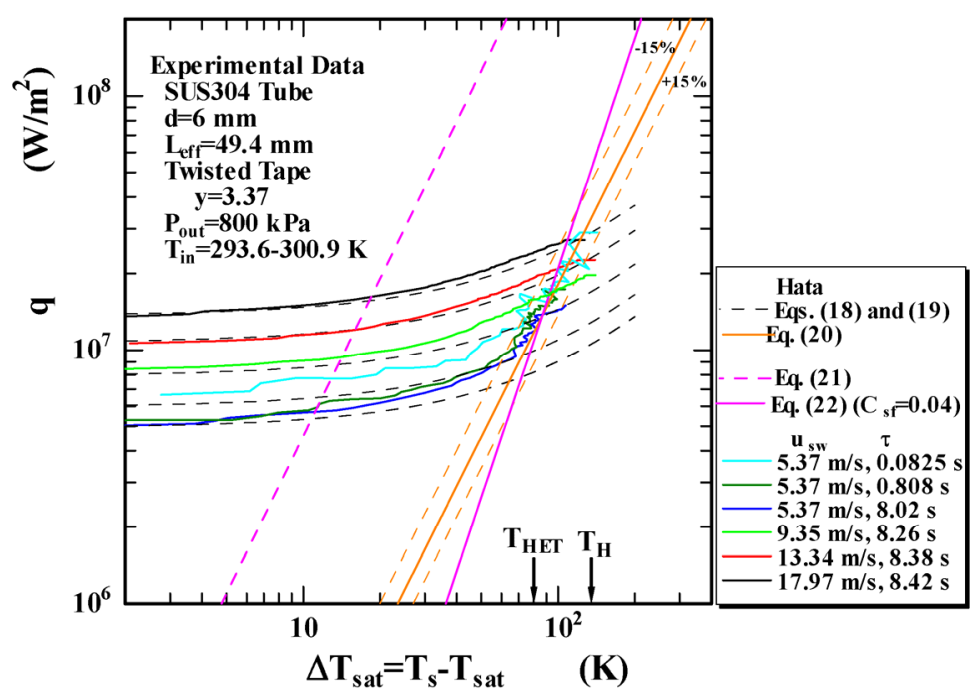

Fig. 6 Typical heat transfer processes for the SUS304 test tube of $d=6 \mathrm{~mm}$ and $L_{\text {eff }}=49.4 \mathrm{~mm}$ with the twisted tape of $y=3.37$ at $u_{s w}=5.37$ to $17.97 \mathrm{~m} / \mathrm{s}$ on $\tau=0.083$ to $8.42 \mathrm{~s}$

Outlet Subcooling $\left(\Delta T_{\text {sub,out }}\right)$

Inlet Liquid Temperature $\left(T_{i n}\right)$

Exponentially Increasing Heat Input $(Q)$

Non-dimensional exponential period $\left(p^{*}\right)$
113.75 to $149.73 \mathrm{~K}$

293.55 to $300.85 \mathrm{~K}$

$Q_{0} \exp (t / \tau), \tau=26.85 \mathrm{~ms}$ to $8.42 \mathrm{~s}$

48.21 to $5.052 \times 10^{4}$

\subsection{Heat Transfer Characteristics}

Figure 6 shows typical examples of the heat transfer curves for the SUS304 test tube of $d=6 \mathrm{~mm}$ and $L_{\text {eff }}=49.4 \mathrm{~mm}$ with the twisted tape of the twist ratio, $y$, of 3.37 on the inlet liquid temperatures, $T_{i n}$, of 293.6 to $300.9 \mathrm{~K}$ and the exponential periods, $\tau$, ranging from 0.083 to $8.4 \mathrm{~s}$ at the swirl velocities, $u_{s w}$, of $5.37,9.35,13.34$ and $17.97 \mathrm{~m} / \mathrm{s}$. At the swirl velocity of $5.37 \mathrm{~m} / \mathrm{s}$, the heat flux gradually becomes higher with an increase in surface superheat, $\Delta T_{\text {sat }}\left(=T_{s}-T_{\text {sat }}\right)$, on the non-boiling forced convection curve derived from authors' correlations of the transient turbulent heat transfer for the circular tube with the twisted-tape insert, Eqs. (18) and (19), ${ }^{(12,18)}$ up to the point where the slope begins clearly to increase with heat flux following the onset of nucleate boiling. After that the heat flux increases along the fully developed nucleate boiling curve on the graph up to the CHF, at which the transition to film boiling occurs with the rapid increasing of surface superheat. At swirl velocities of $9.35,13.34$ and $17.97 \mathrm{~m} / \mathrm{s}$, the heat flux gradually becomes higher with an increase in $\Delta T_{\text {sat }}$ on the non-boiling forced convection curve derived from authors' correlations, Eqs. (18) and (19). After that the slope on the boiling curve does not increase with heat flux even following the onset of nucleate boiling up to the CHF, although the violent boiling noise was made for a period of time before the CHF point. The CHF and its surface superheat, $\Delta T_{\text {sat }}$, become higher with an increase in swirl velocity.

$$
\begin{aligned}
& N u_{d}=0.02 \operatorname{Re}_{s w}^{0.85} \operatorname{Pr}^{0.4}\left(\frac{L_{e f f}}{d}\right)^{-0.08}\left(\frac{\mu_{l}}{\mu_{w}}\right)^{0.14}\left(1+9.46 p^{*-0.8}\right) \\
& \operatorname{Re}_{s w}=\rho_{l} u_{s w} d / \mu_{l}
\end{aligned}
$$

The fully developed nucleate boiling curve up to CHF for SUS304 test tube of $d=6 \mathrm{~mm}$ and $L_{\text {eff }}=49.4 \mathrm{~mm}$ with the twisted tape of $y=3.37$ has been expressed by the empirical correlation, Eq. (20), at the swirl velocitis, $u_{s w}$, ranging from 5.37 to $17.97 \mathrm{~m} / \mathrm{s}$.

$$
q=C \Delta T_{\text {sat }}^{n}=1814 \Delta T_{\text {sat }}^{2}
$$

The correlation can almost describe the fully developed nucleate boiling curves and the heat transfer curves up to CHF for the swirl velocities of 5.37 and $17.97 \mathrm{~m} / \mathrm{s}$ and the transient nucleate boiling curves for the exponential periods, $\tau$, ranging from 0.083 to $8.4 \mathrm{~s}$ at the outlet pressure of around $800 \mathrm{kPa}$ obtained in this work within $\pm 15 \%$ difference.

The corresponding curves derived from the correlations for incipient boiling superheat given by Bergles and Rohsenow ${ }^{(19)}$ and fully developed subcooled boiling in empty circular tubes given by Rohsenow ${ }^{(20)}$ are also shown in Fig. 6 for comparison. 

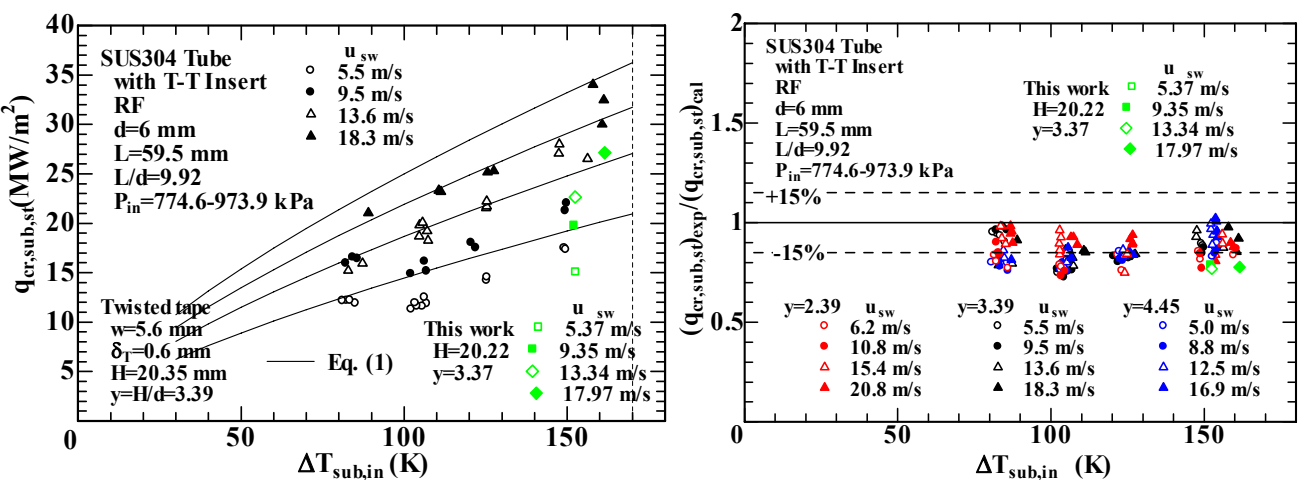

Fig. $7 q_{c, s u b, s t}$ vs. $\Delta T_{\text {sub,in }}$ for SUS304 test tube of Fig. 8 Ratio of CHF data for SUS304 test tubes of $d=6 \mathrm{~mm}$ and $L=59.5 \mathrm{~mm}$ with the twisted-tape of $d=6 \mathrm{~mm}$ and $L=59.5 \mathrm{~mm}$ with the twisted-tapes of $y=3.39$ at $P_{\text {in }}=775$ to $974 \mathrm{kPa}$

$$
\begin{aligned}
& \left(\Delta T_{s a t}\right)_{O N B}=0.556\left(\frac{q}{1082 P^{1.156}}\right)^{0.463 P^{0.0234}} \\
& \frac{c_{p l} \Delta T_{s a t}}{h_{f g}}=C_{s f}\left(\frac{q}{\mu_{l} h_{f g}} \sqrt{\frac{\sigma}{g\left(\rho_{l}-\rho_{g}\right)}}\right)^{0.33}\left(\frac{c_{p l} \mu_{l}}{\lambda_{l}}\right)^{1.7} \text { with } C_{s f}=0.04
\end{aligned}
$$

The values of the lower limit of the heterogeneous spontaneous nucleation temperature $T_{H E T}{ }^{(21)}$ and the homogeneous spontaneous nucleation temperature, $T_{H},{ }^{(22)}$ at the pressure of $800 \mathrm{kPa}$ are shown in Fig. 6 for comparison. The inner surface temperature of the test tube at CHF with the swirl velocity, $u_{s w}$, of $17.97 \mathrm{~m} / \mathrm{s}$ is almost $26.7 \mathrm{~K}$ higher and $28.0 \mathrm{~K}$ lower than the lower limit of the heterogeneous spontaneous nucleation temperature and the homogeneous spontaneous nucleation temperature, respectively.

\subsection{Steady-state CHF characteristics for SUS304-tube with twisted-tape insert ${ }^{(10,11)}$}

\subsubsection{In case of inlet subcooling}

The steady-state CHFs, $\mathrm{q}_{\mathrm{cr} \text { sub,st }}$, for the SUS304 test tube of $d=6 \mathrm{~mm}$ and $L=59.5 \mathrm{~mm}$ with the twisted-tape of $y=3.39$ were shown versus the inlet subcooling, $\Delta T_{\text {sub,in }}$, with the swirl velocities, $u_{s w}$, of 5.5 to $18.3 \mathrm{~m} / \mathrm{s}$ in Fig. $7^{(10,11)}$. The $q_{c r, s u b, s t}$ for each swirl velocity become higher with an increase in $\Delta T_{s u b, i n}$. The increasing rate becomes lower for higher $\Delta T_{\text {sub,in. }}$. The $q_{c r, s u b, s t}$ increase with an increase in the swirl velocity at a fixed $\Delta T_{\text {sub,in. }}$. The $q_{c r s u b, s t}$ for the wide range of swirl velocities are almost proportional to $\Delta T_{s u b, i n}{ }^{0.7}$ for $\Delta T_{\text {sub, in }} \geq 40 \mathrm{~K}$. The curves derived from Eq. (1) are shown in Fig. 7 for comparison. The $\mathrm{CHF}$ data for $\Delta T_{\text {sub,in }} \geq 40 \mathrm{~K}$ are almost in good agreement with the values given by this correlation. This equation is composed of the same terms, exponents and constants except for a transient term as shown in the transient CHF correlation against inlet subcooling for the empty test tube, Eq. (5).

To confirm the applicability of Eq. (1), the ratios of these CHF data for SUS304 test tubes of $d=6 \mathrm{~mm}$ with the twisted-tapes of $y=2.39,3.39$ and 4.45 (179 points) to the corresponding values calculated by Eq. (1) are shown versus $\Delta T_{\text {sub,in }}$ in Fig. 8. Most of the data for $\Delta T_{\text {sub,in }} \geq 40 \mathrm{~K}$ are within -25 to $0 \%$ diffrence of Eq. (1) for the wide ranges of twist ratios, inlet subcoolings and swirl velocities.

\subsubsection{In case of outlet subcooling}

Figure 9 shows the steady-state CHFs, $q_{c r, s u b, s t}$, versus the outlet subcoolings, $\Delta T_{\text {sub,out }}$, for the SUS304 test tube of $d=6 \mathrm{~mm}$ and $L=59.5 \mathrm{~mm}$ with the twisted-tape of $y=3.39$ obtained for the swirl velocities, $u_{s w}$, ranging from 5.5 to $18.3 \mathrm{~m} / \mathrm{s}$ at the outlet pressure, $P_{\text {out }}$, of around $800 \mathrm{kPa}{ }^{(10,11)}$. As shown in the figure, the $q_{c r, s u b, s t}$ for each swirl velocity become also higher with an increase in $\Delta T_{\text {sub,out }}$ and the increasing rate becomes lower for higher $\Delta T_{\text {sub,out }}$. The CHFs in the whole experimental range become higher with an increase in the swirl velocity at a fixed $\Delta T_{\text {sub,out }}$. The curves given by Eq. (2) at each swirl velocity are shown in Fig. 9 for comparison. The CHF data for $\Delta T_{\text {sub,out }} \geq 30 \mathrm{~K}$ are in good agreement with the values given by the correlation. Equation (2) was derived based on the experimental data for $d=6 \mathrm{~mm}, L=59.5 \mathrm{~mm}, \quad L / d=9.92$ and $\delta=0.5 \mathrm{~mm}$ with the twisted-tape 

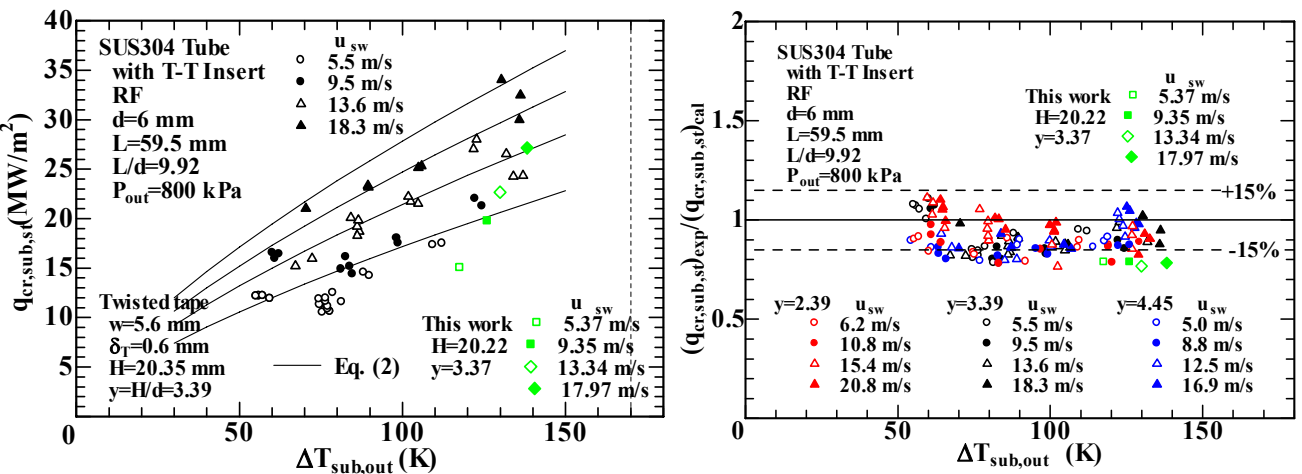

Fig. $9 q_{c r, s u b, s t}$ vs. $\Delta T_{\text {sub }, \text { out }}$ for SUS304 test tube of Fig. 10 Ratio of CHF data for SUS304 test tubes of $d=6 \mathrm{~mm}$ and $L=59.5 \mathrm{~mm}$ with the twisted-tape of $d=6 \mathrm{~mm}$ and $L=59.5 \mathrm{~mm}$ with the twisted-tapes of $y=3.39$ at $P_{\text {out }} \cong 800 \mathrm{kPa}$ $y=2.39,3.39$ and 4.45 to the values derived from the outlet CHF correlation for the test tube with various twisted-tape inserts versus $\Delta T_{\text {sub.out }}$ at $P_{\text {ou }} \cong 800 \mathrm{kPa}$

of $y=3.39$ at the swirl velocities ranging from 5.4 to $18.3 \mathrm{~m} / \mathrm{s}$. This equation is also composed of the same terms, exponents and constants except for a transient term as shown in the transient CHF correlation against outlet subcooling for the empty test tube, Eq. (6).

To confirm the applicability of Eq. (2) to the data for the wide ranges of twist ratios, swirl velocities and outlet subcoolings, the ratios of these CHF data for SUS304 test tubes of $d=6 \mathrm{~mm}$ with the twisted-tapes of $y=2.39,3.39$ and 4.45 to the corresponding values calculated by Eq. (2) are shown versus $\Delta T_{\text {sub.out }}$ in Fig. 10. Most of the data for $d=6 \mathrm{~mm}$ with the twisted-tapes of $y=2.39,3.39$ and 4.45 (179 points) are within -20 to $+10 \%$ difference for $5.0 \mathrm{~m} / \mathrm{s} \leq u_{s w} \leq 20.8 \mathrm{~m} / \mathrm{s}$ and $55.2 \mathrm{~K} \leq \Delta T_{\text {sub,out }} \leq 137.0 \mathrm{~K}$.

\subsection{Transient CHF characteristics for empty SUS304-tube ${ }^{(13-15)}$}

We have already measured the transient CHFs, $q_{c r, s u b}$, (473 points) on an empty SUS304-tube for the exponentially increasing heat input with a wide range of exponential periods, $\tau,\left(Q=Q_{0} \exp (t / \tau), \tau=16.82 \mathrm{~ms}\right.$ to $\left.15.52 \mathrm{~s}\right)$. It has been clarified that the ratios of the difference between the transient CHFs and the steady-state ones to the steady-state ones, $\left(q_{c r, s u b}-q_{c r, s u b, s t}\right) / q_{c r, s u b, s t}$, are almost proportional to $\tau^{-0.6}$ for fixed $\Delta T_{\text {sub,in }}$ and $u$. These data can be expressed by the empirical correlation, Eq. (23), as shown in Fig. 11.

$$
\frac{q_{c r, s u b}-q_{c r, s u b, s t}}{q_{c r, s u b, s t}}=11.4 p^{*-0.6}
$$

where $p^{*}$ is the non-dimensional exponential period, $p^{*}=\tau u /\left\{\sigma / g /\left(\rho_{l}-\rho_{g}\right)\right\}^{0.5}$. We have given the transient CHF correlations against inlet and outlet subcoolings, Eqs. (5) and (6), on the basis of the effect of the non-dimensional exponential period for the inner diameters of 3, 6, 9 and $12 \mathrm{~mm}$ and the heated lengths of 33.15 to $132.9 \mathrm{~mm}$ with $L / d=5.48$ to 11.075 at the outlet pressures of around 800 and $1100 \mathrm{kPa}$. Most of the data (473 points) are within $15 \%$ difference of Eqs. (5) and (6) for wide non-dimensional exponential period as shown in Figs. 12 and $13^{(13-15)}$.

\subsection{Transient CHF characteristics for SUS304-tube with twisted-tape Insert}

The transient CHFs, $q_{c r \text { sub }}$, of the subcooled water flow boiling for the wide ranges of the exponentially increasing heat inputs $\left(Q_{0} \exp (t / \tau), \quad \tau=26.85 \mathrm{~ms} \quad\right.$ to $\left.8.42 \mathrm{~s}\right), \quad$ the mass
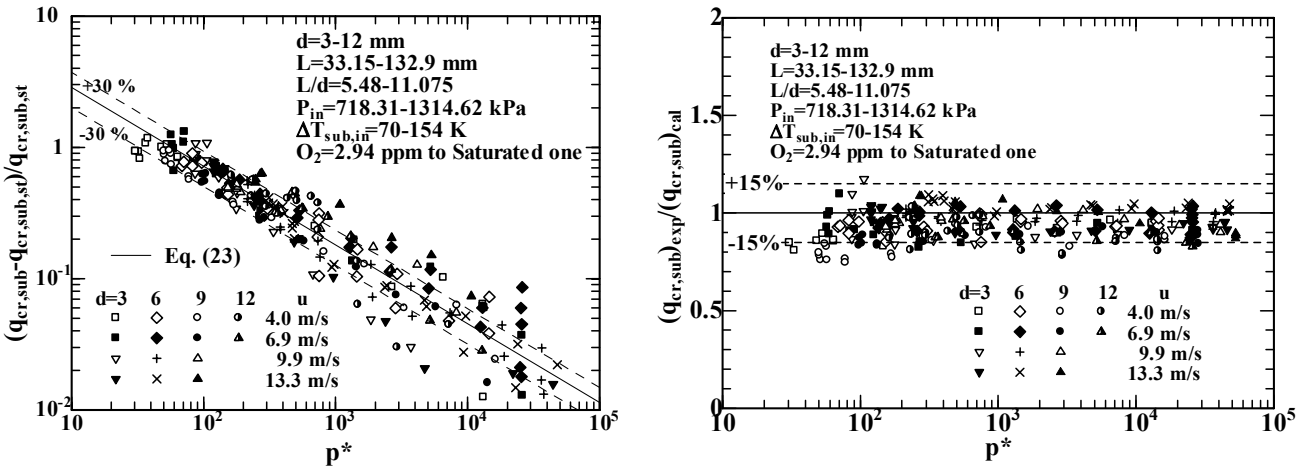

Fig. $11\left(q_{c r, s u b}-q_{c r, s u b, s t}\right) / q_{c r, s u b, s t}$ for $d=3,6,9$ and 12 Fig. 12 Ratios of $q_{c r, s u b}$ for $d=3,6,9$ and $12 \mathrm{~mm}$ (473 $\mathrm{mm}$ versus $p^{*}$ with $u=4.0$ to $13.3 \mathrm{~m} / \mathrm{s}$ at $P_{i n}=718$ to points) to corresponding values calculated by Eq. (5) $1314 \mathrm{kPa}$ versus $p^{*}$ 


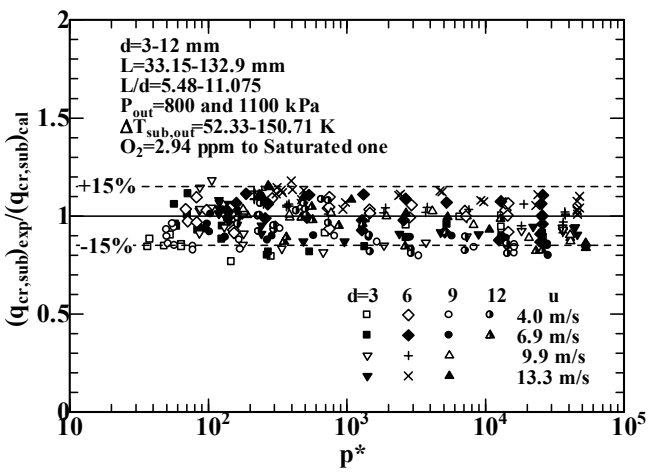

Fig. 13 Ratios of $q_{c r, s u b}$ for $d=3,6,9$ and $12 \mathrm{~mm}(473$ points) to
versus $p^{*}$

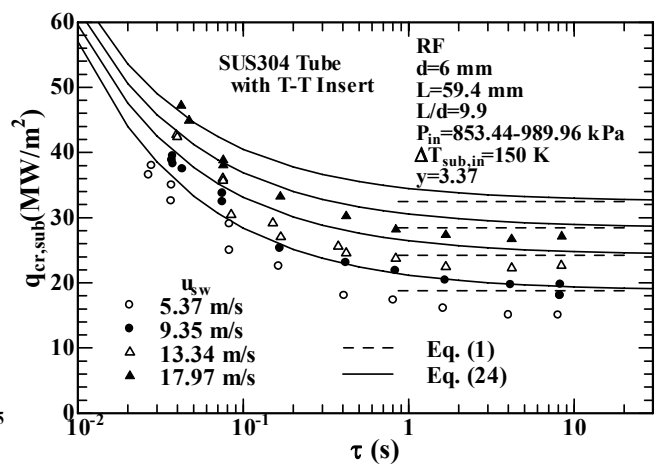

14 The $q_{c r s u b}$ for $d=6 \mathrm{~mm}$ with exponentially increasing heat input at $\Delta T_{\text {sub,in }}=150 \mathrm{~K}$ for $\tau=26.85$ $\mathrm{ms}$ to $8.42 \mathrm{~s}$

velocities $\left(G=3997.79\right.$ to $\left.13419.8 \mathrm{~kg} / \mathrm{m}^{2} \mathrm{~s}\right)$, the inlet subcoolings $\left(\Delta T_{\text {sub }, \text { in }}=149.02\right.$ to 161.54 $\mathrm{K})$ and the inlet pressures $\left(P_{i n}=852.02\right.$ to $\left.989.96 \mathrm{kPa}\right)$ were systematically measured. The SUS304 tube of the inner diameter $(d=6 \mathrm{~mm})$, heated length $(L=59.4 \mathrm{~mm}), L / d=9.9$ and wall thickness $(\delta=0.5 \mathrm{~mm})$ with the rough finished inner surface (Surface roughness, $R a=3.89$ $\mu \mathrm{m})$ were used. The SUS304 twisted-tape of width $(w=5.6 \mathrm{~mm})$, thickness $\left(\delta_{T}=0.6 \mathrm{~mm}\right)$, total length $(l=372 \mathrm{~mm})$ and twist ratio $[y=H / d=3.37]$ was mainly employed.

\subsubsection{In case of inlet subcooling}

The transient CHFs, $q_{c r, s u b}$, for the SUS304 test tube of $d=6 \mathrm{~mm}$ and $L=59.4 \mathrm{~mm}$ with the twisted-tape of the twist ratio, $y$, of 3.37 at the inlet subcooling of around $150 \mathrm{~K}$ are shown versus the exponential period, $\tau$, with the $\tau$ ranging from $26.85 \mathrm{~ms}$ to $8.42 \mathrm{~s}$ at the swirl velocities, $u_{s w}$, of 5.37, 9.35, 13.34 and $17.97 \mathrm{~m} / \mathrm{s}$ in Fig. 14. The figure also illustrates the trends in the variation of transient $\mathrm{CHF}$ with decreasing exponential period. The transient CHFs become higher with a decrease in the exponential period at a fixed $u_{s w}$. The transient CHFs, $q_{c r, s u b}$, are almost constant for the exponential period, $\tau$, higher than around $800 \mathrm{~ms}$ and they become higher with the decrease in the $\tau$. Those show nearly the same trend of dependence on transient CHF data for empty SUS304-tubes of $d=3,6,9$ and 12 $\mathrm{mm}$ with the exponentially increasing heat input ${ }^{(13-15)}$, although the SUS304 twisted-tape of width $(w=5.6 \mathrm{~mm})$, thickness $\left(\delta_{T}=0.6 \mathrm{~mm}\right)$, total length $(l=372 \mathrm{~mm})$ and twist ratio $\left[y=H / d=\left(\right.\right.$ pitch of $180^{\circ}$ rotation $\left.) / d=3.37\right]$ is inserted in the SUS304 test tube of $d=6 \mathrm{~mm}$ and $L=59.4 \mathrm{~mm}$. The transient CHFs in the whole experimental range become higher with an increase in swirl velocity at a fixed $\tau$. The curves given by the steady-state CHF correlation against inlet subcooling for a SUS304-circular tube with various twisted-tape inserts, Eq. (1), at each swirl velocity are shown in Fig. 14 for comparison. The transient CHF data for the $\tau$ higher than $800 \mathrm{~ms}$ are $-22 \%$ lower than the values given by Eq. (1).

The steady-state CHFs, $q_{c r, s u b, s t}$, for the $u_{s w}$ of $5.37,9.35,13.34$ and $17.97 \mathrm{~m} / \mathrm{s}$ at the $\tau$ of around $8 \mathrm{~s}$ are shown as each green symbols in Figs. 7 to 10. Most of the steady-state CHF data are $-22 \%$ lower than the values calculated from the steady-state CHF correlations against inlet and outlet subcoolings for the test tubes with various twisted-tape inserts, Eqs. (1) and (2). The transient CHF experiments with rapidly increasing temperature are very severe for test tube and these SUS304 tubes were not the same serial number but the same manufacturer. It is considered especially in case of SUS304 tube with the twisted-tape insert that the surface temperature at the heterogeneous spontaneous nucleation would become higher due to a confined space effect associated with the twisted-tape at transient CHF. And furthermore, the difference and variation between both surface conditions such as surface roughness and surface wettability would play an important role in nucleate boiling heat transfer and transient CHF. We have supposed that the test tube surface for Test Tube Number of THD-F190 in this work would generally become a lower CHF characteristic because the steady-state CHF data at the $\tau$ of around $8 \mathrm{~s}$ are $22 \%$ lower than the values calculated from the general coleerations for the steady-state CHF from the test tubes with various twisted-tape inserts, Eqs. (1) and (2).

Figure 15 shows a typical photograph for SUS304 test tube of $d=6 \mathrm{~mm}$ and $L=59.4$ $\mathrm{mm}$ with the twisted-tape of $y=3.37$ burned out in transient CHF experiment. The dark sections in the middle of the test tube are the traces of the spiral vapor patches with the twisted-tape of $y=3.37$ which would have become high temperature right beneath the twisted-tape edge; the local temperatures on the tube jumped to those of the film boiling region at the occurrence of CHF. The red-hot surfaces on the test tube at CHF were observed at the $\tau$ of around $8 \mathrm{~s}$. The locations of these vapor patches were almost observed 

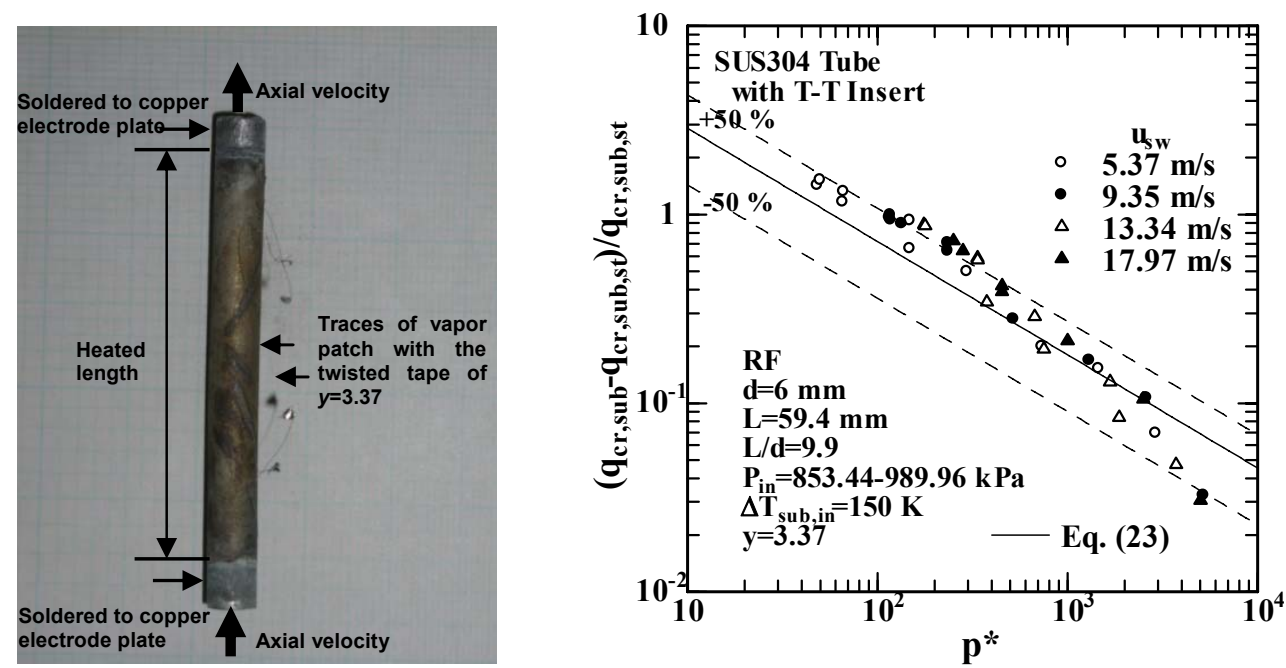

Fig. 15 Typical photograph for SUS304 test tube of $d=6 \mathrm{~mm}$ and $L=59.4 \mathrm{~mm}$ with the twisted-tape of Fig. $16\left(q_{c r, s u b}-q_{c, s u b, s t}\right) / q_{c r, s u b, s t}$ versus $p^{*}$ for $d=6 \mathrm{~mm}$ $y=3.37$ burned out in transient CHF experiment with exponentially increasing heat input

in the middle of the test tube in this transient CHF experiment, not near the tube outlet. It is assumed that the transition to film boiling for Test Tube Number of THD-F190 in this work would occur due to the heterogeneous spontaneous nucleation even at the steady-state CHF with the $\tau$ of around $8 \mathrm{~s}$ but not due to the hydro-dynamic instability. The tube wall did not clearly melt down along the circumference of the tube, because the heating current to the tube was instantaneously cut off when the measured average temperature rapidly increased up to the preset temperature lower than the actual burnout temperature of the tube. By using this burnout detector, several CHF data were obtained for a single tube without the actual burnout.

For power transient experiments, the rate of increasing heat input is very high. It takes time to form the fully developed temperature profile in the test tube because the test tube has some heat capacity. Then the temperature profile in the conductive sub-layer on the test tube surface grows, and vaporization occurs. It also takes some time to occur instantaneously the heterogeneous spontaneous nucleation on the test tube surface at the transient CHF. Namely, it is explained to be as a result of the time lag of the formation of the transient CHF for the increasing rate of the heat input. Figure 16 shows the influence of the non-dimensional exponential period, $p^{*}=\tau u /\left\{\sigma / g /\left(\rho_{l}-\rho_{g}\right)\right\}^{0.5}$, for the exponentially increasing heat input, $\tau$, on the ratios of the difference between the transient CHFs, $q_{c r, s u b}$, and the steady-state ones, $q_{c r, s u b, s t}$, to the $q_{c r, s u b, s t},\left(q_{c r, s u b}-q_{c r, s u b, s t}\right) / q_{c r, s u b, s t}$, for the SUS304 test tube of $d=6 \mathrm{~mm}$ with the twisted-tape of the twist ratio, $y$, of 3.37 at the fixed inlet subcooling of around $150 \mathrm{~K}$. The ratios for the non-dimensional exponential period ranging from 48.21 to $5.196 \times 10^{3}$ were shown versus the $p^{*}$ with the swirl velocity as a parameter. As shown in Fig. 16, the values of $\left(q_{c r, s u b}-q_{c r, s u b, s t}\right) / q_{c r, s u b, s t}$ become linearly higher with the decrease in the non-dimensional exponential period, $p^{*}$. The values of $\left(q_{c r, s u b}-q_{c r, s u b, s t}\right) / q_{c r, s u b, s t}$ obtained from Eq. (23) are shown as solid curve in Fig. 16 for comparison. Equation (23) can also describe these ratios for the $p^{*}$ ranging from 48.21 to $5.196 \times 10^{3}$ (49 points) within $\pm 50 \%$ difference. Equation (23) was derived based on the experimental data on an empty SUS304-tube for the inner diameters of 3, 6, 9 and $12 \mathrm{~mm}$ and the heated lengths of 33.15 to $132.9 \mathrm{~mm}$ with $L / d=5.48$ to 11.075 at the outlet pressures of around 800 and $1100 \mathrm{kPa}$ with the exponentially increasing heat input ${ }^{(13-15)}$.

The transient CHF correlation against inlet subcooling for the test tubes with various twisted-tape inserts is derived due to the effect of boiling number based on swirl velocity, $B o_{c r, s w}$, and Weber number based on swirl velocity, $W e_{s w}$, on the basis of Eq. (23), the steady-state CHF correlation against inlet subcooling for the test tubes with various twisted-tape inserts, Eq. (1) ${ }^{(10,11)}$ and the transient CHF correlation against inlet subcooling for the empty test tubes, Eq. (5) ${ }^{(13-15)}$ as follows:

$$
B o_{c r, s w}=C_{1} D^{*-0.1} W e_{s w}^{-0.3}\left(\frac{L}{d}\right)^{-0.1} e^{-\frac{(L / d)}{C_{2} R e_{d}^{0.4}}} S c^{* C_{3}} \times\left(1+11.4 p^{*-0.6}\right)
$$

if inlet subcooling is known $\left(\Delta T_{s u b, i n} \geq 40 \mathrm{~K}\right)$

The ratios of transient CHF data for the SUS304 test tube of $d=6 \mathrm{~mm}$ with the twisted-tape of the twist ratio, $y$, of 3.37 on the wide exponential periods (49 points) to the corresponding values calculated by the steady-state $\mathrm{CHF}$ correlation against inlet 


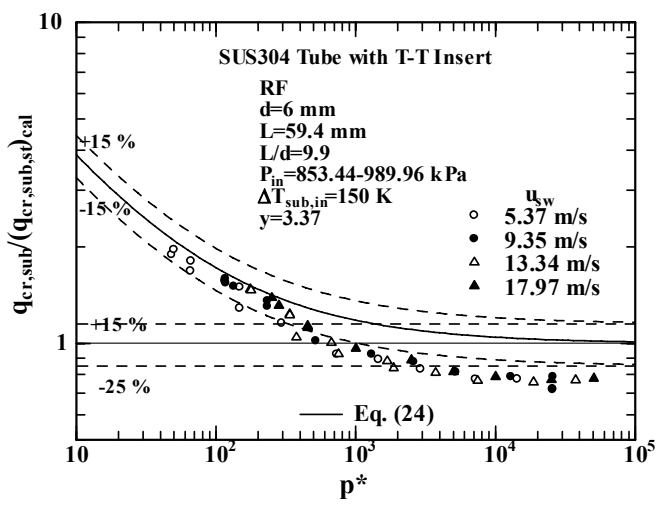

Fig. 17 Ratios of $q_{c, s u b}$ for $d=6 \mathrm{~mm}$ with
exponentially increasing heat input $(49$ points) to exponentially increasing heat input (49 points) to values calculated by Eq. (1) versus $p^{*}$

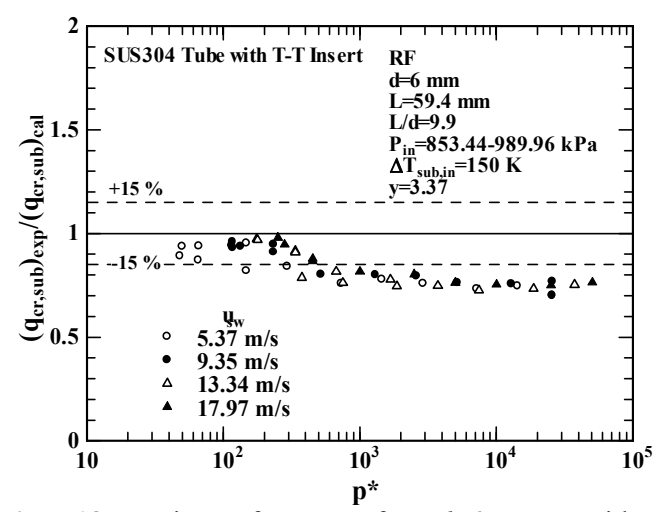

Fig. 18 Ratios of $q_{c r, s u b}$ for $d=6 \mathrm{~mm}$ with exponentially increasing heat input (49 points) to values calculated by Eq. (24) versus $p^{*}$

subcooling for the test tubes with various twisted-tape inserts, Eq. (1), are shown versus the non-dimensional exponential period, $p^{*}$, in Fig. 17. The ratios are almost constant for the $p^{*}$ greater than around 1500 and equivalent to around 0.8 , and it becomes higher with the decrease in non-dimensional exponential period from around 1500. And the values of the transient CHF almost become two times as large as the steady-state ones at the non-dimensional exponential period of 57.8. The curve given by the transient $\mathrm{CHF}$ correlation against inlet subcooling for the test tubes with various twisted-tape inserts, Eq. (24), is shown in Fig. 17 for comparison. The trend of a decrease in transient CHF data with an increase in the non-dimensional exponential period for the wide range of the non-dimensional exponential periods is almost in good agreement with the values given by Eq. (24).

The ratios of transient CHF data for the SUS304 test tube of $d=6 \mathrm{~mm}$ and $L=59.4 \mathrm{~mm}$ $(L / d=9.9)$ with the twisted-tape of the twist ratio, $y$, of 3.37 to the values calculated from the transient CHF correlation against inlet subcooling for the test tubes with various twisted-tape inserts, Eq. (24), are shown versus the $p^{*}$ at the inlet pressures of 853.44 to $989.96 \mathrm{kPa}$ in Fig. 18. This correlation can describe the transient CHF data for the SUS304-tube with the twisted-tape of the twist ratio, $y$, of 3.37 (49 points) obtained in this work for the wide range of the non-dimensional exponential periods ( $p^{*}=48.21$ to $\left.5.052 \times 10^{4}\right)$ and the swirl velocities $\left(u_{s w}=5.37\right.$ to $\left.18.11 \mathrm{~m} / \mathrm{s}\right)$ at $\Delta T_{\text {sub,in }}=$ around $150 \mathrm{~K}$ within -27 to $0 \%$ difference as shown in Fig. 18.

\subsubsection{In case of outlet subcooling}

The transient CHF correlation against outlet subcooling for the test tubes with various twisted-tape inserts is derived due to the effect of boiling number based on swirl velocity, $B o_{c r, s w}$, and Weber number based on swirl velocity, $W e_{s w}$, on the basis of Eq. (23), the steady-state CHF correlation against outlet subcooling for the test tubes with various twisted-tape inserts, Eq. (2) ${ }^{(10,11)}$ and the transient CHF correlation against outlet subcooling for the empty test tubes, Eq. (6) ${ }^{(13-15)}$ as follows:

$$
B o_{c r, s w}=0.082 D^{*-0.1} W_{s w}^{-0.3}\left(\frac{L}{d}\right)^{-0.1} S c^{0.7} \times\left(1+6.34 p^{*-0.6}\right)
$$

if outlet subcooling is known $\left(\Delta T_{\text {sub,out }} \geq 30 \mathrm{~K}\right)$

The ratios of transient CHF data for the SUS304 test tube of inner diameter $(d=6 \mathrm{~mm})$, heated length $(L=59.4 \mathrm{~mm})$ and $L / d(=9.9)$ with the twisted tape of the twist ratio, $y$, of 3.37 to the values calculated from the steady-state CHF correlation against outlet subcooling for the test tubes with various twisted-tape inserts, Eq. (2), are shown versus $p^{*}$ with $\Delta T_{\text {sub,out }}$ ranging from 113.75 to $149.73 \mathrm{~K}$ at the outlet pressure of around $800 \mathrm{kPa}$ in Fig. 19. The ratios for the SUS304 test tube of $d=6 \mathrm{~mm}$ with twisted-tape insert are also constant for the non-dimensional exponential period, $\mathrm{p}^{*}$, higher than 500 and equivalent to around 0.8 , and they become higher with the decrease in the non-dimensional exponential period from around 500. And in case of the exponentially increasing heat input, the values of the transient CHF also become two times as large as the steady-state ones at the non-dimensional exponential period of around 21.7. The curve given by the transient CHF correlation against outlet subcooling for the test tubes with various twisted-tape inserts, Eq. (25), is shown in Fig. 19 for comparison. The trend of a decrease in CHF data with an increase in the non-dimensional exponential period for the wide range of the non-dimensional exponential periods are almost in good agreement with the values given by 

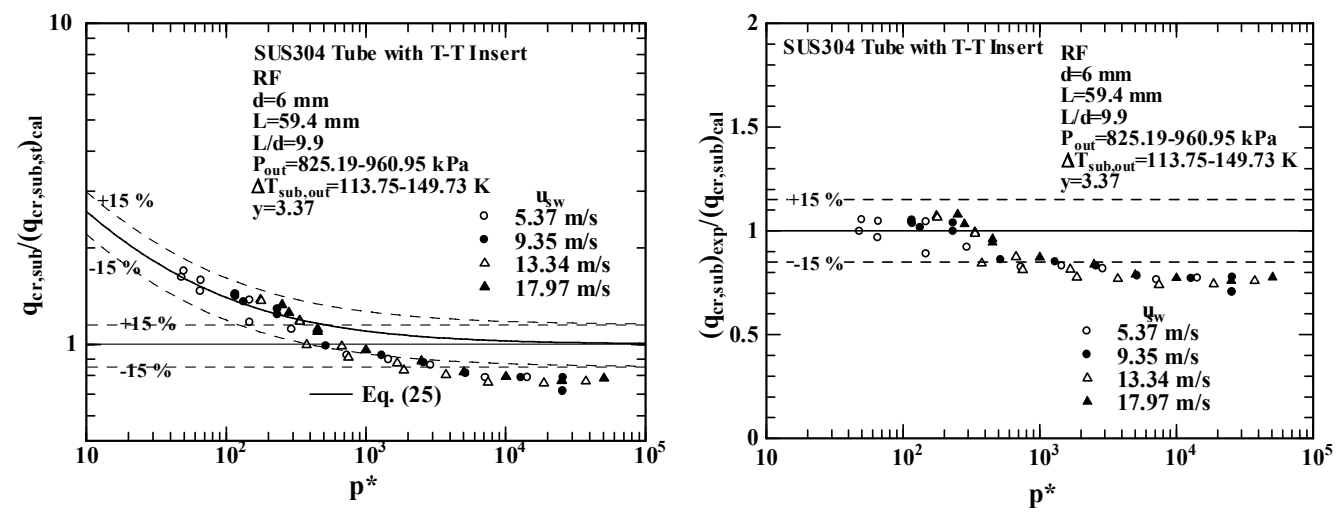

Fig. 19 Ratios of $q_{c r, s u b}$ for $d=6 \mathrm{~mm}$ with Fig. 20 Ratios of $q_{c r, s u b}$ for $d=6 \mathrm{~mm}$ with exponentially increasing heat input (49 points) to exponentially increasing heat input (49 points) to values calculated by Eq. (2) versus $p^{*}$ values calculated by Eq. (25) versus $p^{*}$

Eq. (25).

The transient CHF correlation against outlet subcooling for the test tubes with various twisted-tape inserts, Eq. (25), was derived based on the experimental data for the exponentially increasing heat input, $Q_{0} \exp (t / \tau)$, with $\tau$ ranging from $26.85 \mathrm{~ms}$ to $8.42 \mathrm{~s}$. To confirm the applicability of Eq. (25) to the transient CHF data for exponentially increasing heat input, the ratios of these CHF data (49 points) for the SUS304 test tube of $d=6 \mathrm{~mm}$ with the twisted-tape of the twist ratio, $y$, of 3.37 to the corresponding values calculated by Eq. (25) are shown versus $p^{*}$ in Fig. 20. Most of the transient CHF data are within -22 to $7.9 \%$ difference for $48.21 \leq p^{*} \leq 5.052 \times 10^{4}$.

\section{Conclusions}

The transient critical heat fluxes (transient CHFs) of subcooled water flow boiling in a SUS304-circular tube for the inner diameter $(d=6 \mathrm{~mm})$, the heated length $(L=59.4 \mathrm{~mm})$, the effective length $\left(L_{e f f}=49.4 \mathrm{~mm}\right), L / d(=9.9), L_{e f f} / d(=8.23)$ and the wall thickness $(\delta=0.5 \mathrm{~mm})$ with the twisted-tape of width $(w=5.6 \mathrm{~mm})$, thickness $\left(\delta_{T}=0.6 \mathrm{~mm}\right)$, total length $(l=372 \mathrm{~mm})$ and twist ratio, $y\left[H / d=\left(\right.\right.$ pitch of $180^{\circ}$ rotation $\left.) / d\right]$, of 3.37 were systematically measured for the mass velocities ( $G=3997.79$ to $13419.8 \mathrm{~kg} / \mathrm{m}^{2} \mathrm{~s}$ ), the inlet liquid temperatures $\left(T_{\text {in }}=293.55\right.$ to $\left.300.85 \mathrm{~K}\right)$, the outlet pressures $\left(P_{\text {out }}=825.19\right.$ to $\left.860.95 \mathrm{kPa}\right)$ and the exponentially increasing heat inputs $\left(Q=Q_{0} \exp (t / \tau), \tau=26.85 \mathrm{~ms}\right.$ to $\left.8.42 \mathrm{~s}\right)$. Experimental results lead to the following conclusions.

1) The transient CHFs, $q_{c r, s u b}$, are almost constant for the exponential period, $\tau$, greater than around $800 \mathrm{~ms}$ and they become higher with the decrease in the $\tau$. The transient CHFs in the whole experimental range become higher with an increase in swirl velocity at a fixed $\tau$.

2) The ratios of the difference between the transient CHFs, $q_{c r, s u b}$, and the steady-state ones, $q_{c r, s u b, s t}$, to the $q_{c r, s u b, s t},\left(q_{c r, s u b}-q_{c r, s u b, s t}\right) / q_{c r, s u b, s t}$, become linearly higher with the decrease in the non-dimensional exponential period, $p^{*}$. Those for the $p^{*}$ ranging from 48.21 to $5.196 \times 10^{3}$ are almost in good agreement with the values obtained by Eq. (23). Equation (23) can also describe these ratios for the $p^{*}$ ranging from 48.21 to $5.196 \times 10^{3}$ (49 points) within $\pm 50 \%$ difference.

3) The ratios of transient CHF data on the wide exponential periods (49 points) to the corresponding values calculated from the steady-state CHF correlations against inlet and outlet subcoolings for the test tubes with various twisted-tape inserts, Eqs. (1) and (2), are almost constant for the non-dimensional exponential period, $p^{*}$, greater than 1500 and 500 , and equivalent to around 0.8 , and they become higher with the decrease in non-dimensional exponential period from 1500 and 500, respectively. And the values of the transient CHF almost become two times as large as the steady-state ones at the non-dimensional exponential periods of 57.8 and 21.7 , respectively.

4) The transient CHF correlations against inlet and outlet subcoolings for the test tubes with various twisted-tape inserts are derived due to the effect of boiling number based on swirl velocity, $B o_{c r, s w}$, and Weber number based on swirl velocity, $W e_{s w}$, on the basis of Eq. (23), the steady-state CHF correlations for the test tubes with various twisted-tape inserts, Eqs. (1) and (2) ${ }^{(10,11)}$ and the transient CHF correlations for the empty test tubes, Eqs. (5) and (6) ${ }^{(13-15)}$. Most of the transient CHF data for SUS304 test tube of $d=6 \mathrm{~mm}$ with the twisted-tape of the twist ratio, $y$, of 3.37 (49 points) are within -27 to $0 \%$ difference of Eq. (24) and within -22 to $7.9 \%$ one of Eq. (25) for the wide ranges of non-dimensional 
exponential periods $\left(p^{*=}=48.21\right.$ to $\left.5.052 \times 10^{4}\right)$, inlet subcoolings $\left(\Delta T_{\text {sub,in }}=149.02\right.$ to 161.54 $\mathrm{K})$, outlet subcoolings $\left(\Delta T_{\text {sub,out }}=113.75\right.$ to $\left.149.73 \mathrm{~K}\right)$ and swirl velocities $\left(u_{s w}=5.37\right.$ to $18.11 \mathrm{~m} / \mathrm{s})$.

\section{Acknowledgments}

This research was performed as a LHD joint research project of NIFS (National Institute for Fusion Science), Japan, NIFS11KEMF015, 2011 and 2012. This research was supported by a Grant-in-Aid for Scientific Research from Japan Society for the Promotion of Science (22560196), 2011 and 2012.

\section{References}

(1) Gambill, W. R., Bundy, R.D., and Wansbrough, R. W., 1961, "Heat Transfer, Burnout, and Pressure Drop for Water in Swirl Flow Tubes with Internal Twisted Tapes," Chem. Eng. Prog. Symp. Ser, 57 (32), pp. 127-137.

(2) Blatt, T. A., and Adt, R. R., 1963, "The Effects of Twisted Tape Swirl Generators on the Heat Transfer Rate and Pressure Drop of Boiling Freon 11 and Water," ASME-63-WA-42.

(3) Lopina, R. F., and Bergles, A.E., 1973, "Subcooled Boiling of Water in Tape Generated Swirl Flow," J. Heat Transfer, 95, pp. 281-283.

(4) Celata, G. P., 1993, "Recent Achievements in the Thermal Hydraulics of High Heat Flux Components in Fusion Reactors," Experimental Thermal and Fluid Science, 7, pp. 263-278.

(5) Tong, W., Bergles, A. E., and Jensen, M. K., 1996, "Critical Heat Flux and Pressure Drop of Subcooled Flow Boiling in Small-Diameter Tubes with Twisted-tape Inserts," Journal of Enhanced Heat Transfer, 3, No. 2, pp. 95-108.

(6) Kabata, Y., Nakajima, R. and Shioda, K., 1996, "Enhancement of Critical Heat Flux for Subcooled Flow Boiling of Water in Tubes with a Twisted Tape and with a Helically Coiled Wire," Proc. of the ASME-JSME 4th International Conference on Nuclear Engineering, Book No. I389A2-1996, pp. 639-646.

(7) Inasaka, F., and Nariai, H., 1996, "Evaluation of subcooled critical heat flux correlations for tubes with and without internal twisted tapes," Nuclear Engineering and Design, 163, pp. 225-239.

(8) Manglik, R. M., and Bergles, A. E., 2002, Swirl Flow Heat Transfer and Pressure Drop with Twisted-Tape Inserts, Advances in Heat Transfer, 36, Academic Press, NewYork, pp. $183-266$.

(9) Bejan, A., and Kraus, A. D., 2003, Heat Transfer Handbook, John Wiley \& Sons, p. 1029.

(10) Hata, K., and Masuzaki, S., 2011, "Subcooled Water Flow Boiling Heat Transfer in a Short SUS304-Tube with Twisted-Tape Insert," Journal of Engineering for Gas Turbines and Power, Trans. ASME, 133,pp. 052906-1-11.

(11) Hata, K. and Masuzaki, S., 2011, "Heat Transfer and Critical Heat Flux of Subcooled Water Flow Boiling in a SUS304-Tube with Twisted-Tape Insert," Journal of Thermal Science and Engineering Applications, Trans. ASME, 3, pp. 012001-1-12.

(12) Hata, K., and Masuzaki, S., 2011, "Twisted-Tape-Induced Swirl Flow Heat Transfer and Pressure Drop in a Short Circular Tube under Velocities Controlled," Nuclear Engineering and Design, 241, pp. 4434-4444.

(13) Hata, K., Shiotsu, M., and Noda, N., 2006, "Influence of Heating Rate on Subcooled Flow Boiling Critical Heat Flux in a Short Vertical Tube," JSME International Journal, Series B, 49, No. 2, pp. 309-317.

(14) Hata, K., and Noda, N., 2008, "Transient Critical Heat Fluxes of Subcooled Water Flow Boiling in a Short Vertical Tube Caused by Exponentially Increasing Heat Inputs," Journal of Heat Transfer, Trans. ASME, Series C, 130, pp. 054503-1-9.

(15) Hata, K., and Masuzaki, S., 2010, "Influence of Heat Input Waveform on Transient Critical Heat Flux of Subcooled Water Flow Boiling in a Short Vertical Tube," Nuclear Engineering and Design, 240, pp. 440-452.

(16) PHOENICS Japanese Manual, 2010, CHAM-Japan, Tokyo (in Japanese).

(17) Brodkey, R. S., and Hershey, H. C., 1988, Transport Phenomena, McGraw-Hill, p. 568.

(18) Hata, K., Kai, N., Shirai, Y., and Masuzaki, S., 2011 "Transient Turbulent Heat Transfer for Heating of Water in a Short Vertical Tube," Journal of Power and Energy Systems, 5, No. 3, pp. 414-428.

(19) Bergles, A. E., and Rohsenow, W.M., 1964, "The Determination of Forced-Convection Surface-Boiling Heat Transfer," Journal of Heat Transfer, 86, pp. 365-372.

(20) Rohsenow, W. M., 1952, "A Method of Correlating Heat-Transfer Data for Surface Boiling of Liquids," Transactions of ASME, 74, pp. 969-976.

(21) Cole, C., 1979, "Homogeneous and heterogeneous nucleation in Boiling Phenomena," Vol. 1, Stralen, S. van, and Cole, R. eds., Hemisphere Pub. Corp., New York, p. 71.

(22) Lienhard, J. H., 1976, "Correlation of Limiting Liquid Superheat," Chem. Eng. Science, 31, pp. 847-849. 